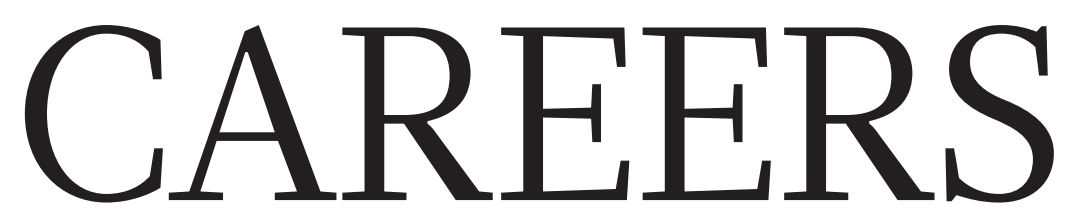

SET UP LAB Negotiate start-up packages and grant applications go.nature.com/gk213b
POSTDOCS Take the next step: how to move on from the bench go.nature.com/eys8hk
NATUREJOBS For the latest career

listings and advice www.naturejobs.com

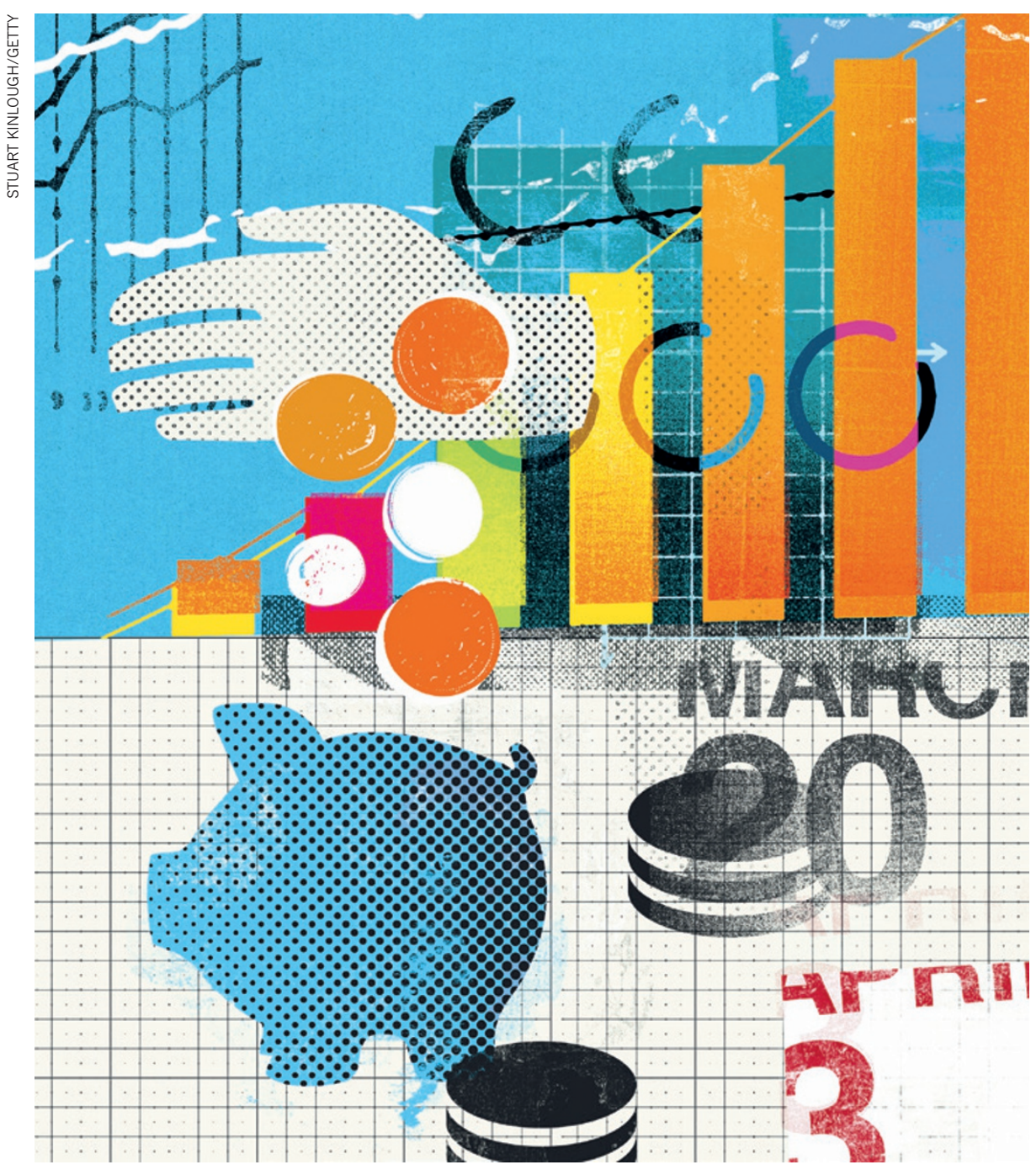

COLUMN

\title{
Respect the report
}

\section{Foundations have reporting requirements that must be followed, notes grant-director Ingrid Eisenstadter.}

$\mathrm{W}$

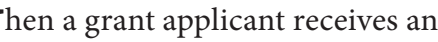
early-career award from a private foundation, she or he enters into a crucial period of communication with the sponsor that will last at least a year, often longer. Foundations - like most granting organizations - have exacting reporting requirements. Grant recipients will have to submit at least one report on the progress of their work, depending on the length of the sponsored research and whether the project changes direction at all.
The recipient of a one-year grant, for example, might need to submit a progress report after six months and a final report once the project is completed. The interim report might be little more than a progress update, whereas the final report will be comprehensive and detailed. Multiple-year grants could call for a single report on completion of the research or successive annual ones. Every foundation has different requirements. And if the research protocol changes or the work requires more time, the researcher should seek approval from the granter as soon as the situation arises.

Foundation-grant recipients need to familiarize themselves with relevant reporting requirements, including formats, deadlines and expected content. These might be spelt out in the covering letter that announces the award, or could be found on the foundation's website. If neither offers answers, grant recipients should consult their contact at the foundation, if they have one, or the person who signed the letter. Failure to follow the foundation's guidelines (or failure to meet a deadline) could jeopardize the recipient's standing with the funder for future proposals (see 'Golden rules for reporting').

\section{PLAN YOUR PATH}

As a grant recipient, you should view the granter's reporting requirements as a map for how to write your reports. A foundation may require researchers to use a prepared template or it may allow you to use your own format. If you are not using a template, take care not to fall into the 'copy-and-paste' habit. From my experience as director of grants for a US family foundation in the sciences, I find that our grant recipients sometimes insert great swaths of their original proposals into their final reports. I suspect that recipients do this to bulk up the report and make it look more thorough.

It does not work. It is clutter, and usually heralds an abbreviated discussion of the actual results and accomplishments. Instead, briefly summarize your work and highlight your victories at the outset, and then explain them in detail in the following pages.

A sensible way to proceed is to address each subsection as it appeared in your proposal. If your proposal listed steps such as 'select a 40-patient cohort, collect weekly blood samples, and sequence viruses', repeat these headings in your report. Under each heading, describe your progress.

Your final report should end with your 
conclusions and their ramifications. If you hope to apply for future support, you might also include 'next steps'.

\section{CHANGE HAPPENS}

Foundations understand that delays can happen: a shortage of supplies, delayed permits for travel or fieldwork, or a team member who has unexpectedly relocated. When this occurs, you should promptly notify your granter and ask for a no-cost extension. This is a fairly common request that requires no additional outlay from the foundation, which will probably not object. In my 25 years at the foundation, we have never denied such a request.

If you are forced to modify your original research protocol, you must notify the foundation. Such a request is unlikely to present problems; we have never denied a request for this type of change. We expect researchers to know better than we do how they should react to an unexpected lab-test result, for instance.

But a major change could cause trouble. If the foundation determines that you are no longer carrying out the work that it wants to support, it could suspend or rescind your grant. I recall only two times when we did not receive prior notification of a major change in research plans. In one case, an animal-migration researcher did not carry out the task that was most important to us - an examination of the harm caused by underwater blasting in oil exploration. In the other, a mouse trial was scaled back to such an extent that it had no hope of progressing to a human trial in the foreseeable future. We viewed the researchers' failure to notify us of such substantial changes as a reflection of lax internal administrative management. We have not funded either organization since then.

You could run the same risk. So before you request a major change in protocol or extra funding, ask colleagues if they know how the foundation operates in those circumstances, or seek advice from your mentor or development office. In rare circumstances, your institution could make up a funding shortage.

\section{ATTENTION TO BUDGET}

Development-office involvement in grant proposals and reports varies substantially between institutions. In some, development staff have little to do with grant applications or reports; in others, they work with research teams to write their grant proposals and reports. If you find yourself depending on these other teams, review their work carefully. Usually, people who do this work are not graduate-level scientists and can introduce mistakes or omit crucial information.

It is important to cross-check reports of your expenditures against the budget you originally submitted and to explain any minor reallocations - which are commonplace — for which you did not seek advance approval. If you reallocate a relatively small amount - US $\$ 500$, or even $\$ 1,000$, in a $\$ 25,000$ budget - you

\section{GOLDEN RULES FOR REPORTING}

\section{What grant recipients should be doing now}

Private foundations might make recurring grants over the years to researchers whose work shows substantial promise. To keep that door open, grant recipients should keep caveats in mind as they create their progress reports.

\section{REMEMBER}

- Speak English. Avoid highly technical language. Private foundations in particular might have non-scientists on their boards and you want them to understand what you have accomplished.

- Circulate to colleagues. Ask co-workers to read reports for content and errors, and get feedback on how well you have captured the importance of your work and whether you have clearly highlighted the significance of your results.

- Future ramifications. No one wants to fund work that will simply sit unread in a library. Explain how your results will drive your future research or that of others.

- Format thoughtfully. Headings and subheadings provide clarity and guidance. Include a table of contents if the report is long.

probably do not need advance approval. If you are unsure, check with your granter first.

Some years ago, we received final reports for two virus studies that we had funded simultaneously at the same organization. The researchers there had not written their own grant proposals or reports; the development office had. Nor had research teams created their budgets; the finance office had. Yet no one had considered the original budgets in the final expense reports: not a single budget line in either recipient's report agreed on cost or designation. As we read the final reports, we could not determine how our funds had been spent. We have not funded that organization since.

If you have leftover funds on completion of your project, seek your granter's permission to hold onto those funds, and explain how you will spend them. Do not assume you can keep the money. Not surprisingly, it is unusual for us to see final reports that indicate surplus funds. Indeed, we sometimes receive final budget reports that agree line for line with the original budget, down to the last dollar. Such tight adherence to budget would require the intervention of the tooth fairy, but it is fairly common. We assume that it resembles reality closely enough.

Writing a final report often coincides with preparations to submit the research for publication. Occasionally, we learn that researchers we have supported have had the first phase of their work published by the time we received their final reports. If this is the case for you, include this information in your final report

\section{AVOID}

- Lateness. Put due dates for interim and final reports in your calendar as soon as the grant is awarded. Add a reminder a month ahead of time and go to the foundation's website to make sure that it has not changed its reporting requirements. - Obscuring the point. Do not start your interim and final reports with a lengthy rehashing of background that was already in your grant proposal. Keep the rest of the report succinct and on point to avoid burying your actual achievements when you should be highlighting them. - Omitting conclusions. State clearly what you learned from your project. If your results were ambiguous or not what you anticipated, that is not a crime. Say so, and describe what you might do in the future to get clarification. I.E.

and, as a courtesy, send links or copies of your future publications to your funder as they appear. Publications in peer-reviewed journals are important to us - we see them as a confirmation of the significance of the work.

\section{RISKY BUSINESS}

From time to time, we receive final reports that ask for renewed funding at the same time. Although researchers may request permission to submit a subsequent grant application with their report, occasionally, they include a new proposal. Jumping the gun in this way carries risk, yet it is understandable. Although some private foundations meet monthly, others meet only semi-annually or annually; waiting for the next formal submission date could substantially delay your follow-up application.

Should you take this initiative? It is a tough call. An unsolicited proposal submission might be considered too forward or the foundation might have a policy not to award another grant until final reports from the previous round have been circulated and reviewed (a process that could take months). If you are in any doubt, contact your sponsoring foundation.

Do not drown your granter with enquiries - always search the foundation's website first. But the occasional request for clarification will reduce your risk and save time for applicant and granter alike.

Ingrid Eisenstadter is director of grants for the Eppley Foundation for Research in New York. 